\title{
A IMPORTÂNCIA DA CONTABILIDADE DE CUSTOS NAS INSTITUIÇÕES FINANCEIRAS DO BRASIL
}

\section{ARTIGO ORIGINAL}

OLIVEIRA, Ricki Duarte Santos de ${ }^{1}$

OLIVEIRA, Ricki Duarte Santos de. A importância da contabilidade de custos nas instituições financeiras do Brasil. Revista Científica Multidisciplinar Núcleo do Conhecimento. Ano 06, Ed. 09, Vol. 05, pp. 56-64. Setembro de 2021. ISSN: $2448-$ 0959, Link de acesso:

https://www.nucleodoconhecimento.com.br/contabilidade/custos-nas-instituicoes, DOI: 10.32749/nucleodoconhecimento.com.br/contabilidade/custos-nas-instituicoes

\section{RESUMO}

O objetivo geral do artigo é discorrer sobre a contabilidade de custos nas instituições financeiras do Brasil, uma vez que ela contribui para o controle dos riscos. O papel da contabilidade de custos nas instituições financeiras tem, no entanto, vindo a mudar a forma de atuação. As instituições financeiras que compõe o Sistema Financeiro Nacional são classificadas e divididas quanto aos seus órgãos e suas operações. O mesmo se justifica, em compreender a importância da contabilidade de custos nas instituições financeiras, pois com o crescimento e desenvolvimento do país, seu foco é na estratégia para minimizar os riscos que envolvem o setor bancário. Diante desta justificativa, o artigo tem a seguinte questão norteadora: Qual a importância da contabilidade de custos nas instituições financeiras do Brasil? Como metodologia, houve uma pesquisa bibliográfica, onde através de autores que discorrem sobre a temática, foi possível concluir o mesmo tendo como base 0 referencial teórico. A principal contribuição deste trabalho é oferecer ao leitor o conhecimento de como a contabilidade de custos é importante nas instituições financeiras do Brasil.

\footnotetext{
${ }^{1}$ Bacharel Em Ciências Contábeis.
}

RC: 97425

Disponível em: https://www.nucleodoconhecimento.com.br/contabilidade/custos-nasinstituicoes 
Palavras-Chave: Contabilidade, Custos, Instituição financeira do Brasil.

\section{INTRODUÇÃO}

As instituições financeiras são consideradas essências para o controle da economia de um país, tendo em vista que nela, a circulação de dinheiro é grande e assim mantém a economia do mesmo.

A atividade de intermediação da instituição financeira exerce importante papéis dentro do panorama do mercado financeiro brasileiro minimizando a incerteza e os riscos tendo que proporcionar cada vez mais segurança e agilidade de melhores retornos a que procura o serviço.

Atualmente essas informações são geradas rapidamente devido à rapidez com que - mundo se transforma e a exigência fazendo com que seja necessária uma atualização constante e elaboração de estratégias para sobrevivência e crescimento pessoal e profissional. Contudo é preciso alguns cuidados nas atividades financeiras pois estão sujeitas a todos os tipos de riscos e para isso a contabilidade de custos tende a desenvolver um processo.

Muitos dos dados para a contabilidade de custo podem se originar fora dos departamentos de custos, pois, além de faturas e de documentos que comprovem as transações dos serviços oferecidos, transferido ou consumido entre os departamentos, o contabilista de custos exige os relatórios dos estudos do tempo, das movimentações, operações, relação de programas e planejamento nas instituições.

Todas instituições financeiras tendem a estarem expostas aos riscos operacionais em que estão caracterizados pela deficiência dos processos, pelos erros humanos, pelas fraudes ou pelas falhas no sistema.

O objetivo geral do artigo é discorrer sobre a contabilidade de custos nas instituições financeiras, uma vez que ela contribui para o controle dos riscos. 
Assim, o mesmo se justifica, em compreender a importância da contabilidade de custos nas instituições financeiras, pois com o crescimento e desenvolvimento do país, seu foco é na estratégia para minimizar os riscos que envolvem o setor bancário.

A questão norteadora que permeia este artigo consiste em refletir sobre a seguinte problemática: Qual a importância da contabilidade de custos nas instituições financeiras?

Como metodologia, haverá uma pesquisa bibliográfica, onde através de autores que discorrem sobre a temática, será possível concluir o mesmo tendo como base o referencial teórico.

\section{INSTITUIÇÕES FINANCEIRAS DO BRASIL}

A existência de instituições financeiras no Brasil desempenha um papel de intermediários, entre as pessoas que permite ao empregar as suas poupanças e aos que procuram capitais nas condições que Ihes convenham, intervindo no mercado de capitais e concedendo créditos para apoiar financeiramente a construção, a produção, ou a aquisição de bens a longo e médio e prazo.

Tais unidades são responsáveis por captar depósitos à vista (moeda escritural ou bancária), e, com a captação realizar operações de empréstimos e financiamentos, as quais poderão ser contratadas com curto e médio prazo, atendendo tanto pessoas físicas quanto pessoas jurídicas. Em função disso, tornam-se multiplicadoras do crédito e criadoras da chamada moeda escritural (ASSAF NETO, 2009, p. 36).

Segundo explica Salomão Neto (2005, p. 27), a aplicação literal da definição constante na lei implicaria alargar em excesso o conceito de instituição financeira, pugnando por uma interpretação teleológica do dispositivo.

As instituições financeiras fazem um grande papel na sociedade, contribuindo com seus serviços aos e fazendo os clientes mais felizes e satisfeitos. A evolução do mundo inteiro quanto ao mercado e sociedade vem velocidade aumentando a cada 
dia que passa e as pessoas coada vez mais precisam recorrer às instituições financeiras para conter a crise que afeta não só os negócios, mas a vida pessoal dos seres humanos.

O Sistema Financeiro Nacional é regulado pela lei 4.595/64 que discorre sobre a regulamentação, funcionamento e políticas das instituições financeiras do país, assim como moeda, crédito, capitais, seguros privados, dentre outros seguimentos. Ao normatizar essas instituições no país, ficou definida nessa legislação de como devem ser estruturadas as condições operacionais. (BRASIL, 1964)

Poucas pessoas sabem que o banco comercial é apenas um dos tipos de instituição financeira que existe. Financeiras, corretoras de valores, bancos de investimento, distribuidoras de valores mobiliários, bancos múltiplos e a Caixa Econômica Federal também são consideradas instituições financeiras.

As instituições financeiras no país funcionam apenas com autorização do Banco Central do Brasil, onde o mesmo é o responsável por sua fiscalização e condições de competições entre essas instituições financeiras. O Conselho Monetário Nacional é o órgão máximo do Sistema Financeiro Nacional e é esse órgão que emite diretrizes para essas instituições financeiras que podem ser públicas ou privadas, onde diferenciam-se apenas pela origem de seus recursos. (BRASIL, 1964)

Estamos sempre precisando de recursos financeiros para isso o mercado disponibiliza de inúmeras instituições financeiras disponíveis, na qual possa atender as necessidades de cada um, seja ela em forma de banco federal, estadual ou até mesmo privado.

Assaf Neto (2009, p. 61) diz que:

A instituição financeira interfere no processo de mediação, sem ter envolvimento direto com os recursos, simplesmente, favorece a realização da transação entre poupadores e tomador de recursos, financiando, desta forma, as necessidades de investimentos, gastos de consumo e capital de giro.

RC: 97425

Disponível em: https://www.nucleodoconhecimento.com.br/contabilidade/custos-nasinstituicoes 
O sigilo nas instituições financeiras, num conceito amplo, consiste em uma obrigação da discrição na qual é imposta as instituições e seus funcionários, para todos os negócios de seus clientes, assim como a quebra deles é necessária quando for autorizada de forma judicial.

A quebra de sigilo se constitui, quando há algum tipo de crime hediondo, onde a justiça determina a averiguação de dados que as instituições são abrigadas a fornecer. Na maioria das vezes a quebra de sigilo bancário, está diretamente ligado ao crime de lavagem de dinheiro, envolvendo as instituições financeiras, passando assim a ser feita de forma sigilosa até o final da investigação.

Nos últimos anos, os avanços tecnológicos, as transações bancárias via internet, a sofisticação de produtos e serviços oferecidos pelos bancos, a ocorrência de escândalos financeiros relacionados a fraudes, entre outros fatos, contribuiu para que instituições financeiras e autoridades reguladoras passassem a dar mais atenção ao risco operacional como um tipo de risco merecedor de tratamento corporativo. (ALVES; CHEROBIN, 2006).

Todos estes riscos tendem a ser agravados na inexistência ou na inadequação nos controles internos, por isso faz-se necessário que haja, na instituição financeira, todo tipo de controle de bens, a começar por uma auditoria interna que fará com que os riscos sejam evitados ou amenizados.

As instituições financeiras podem ser definidas como agentes intermediários que possibilitam a otimização dos capitais, permitindo além da intermediação e da participação em transações financeiras, efetuam a recolha de informação sobre vários ativos e investimentos, que pode ser vendida a outros investidores (FERREIRA, 2012).

De acordo com o Banco Central do Brasil, as instituições financeiras que compõe o Sistema Financeiro Nacional são classificadas e divididas quanto aos seus órgãos normatizadores e supervisores, e quanto as suas operações. 


\section{CONTABILIDADE DE CUSTOS EM INSTITUIÇÕES FINANCEIRAS DO BRASIL}

Contabilidade de custos nada mais é uma subdivisão da Contabilidade Geral numa organização, também se dedica a um estudo racional de gastos que são feitos, para alcançar um bem em vendas ou consumo, seja produto, mercadoria ou até mesmo um serviço.

Atualmente, além de fazerem a intermediação no sistema financeiro, as instituições dedicam-se a muitas outras tarefas, como é o caso, do fornecimento de produtos e serviços personalizados e da gestão de riscos. O papel da contabilidade de custos nas instituições financeiras tem, no entanto, vindo a mudar a forma de atuação.

O papel das instituições financeiras no tempo atuais tem, apesar de grandes mudanças ao longo do tempo é o de fazer a intermediação no sistema financeiro, onde as dedicando-se a muitas outras tarefas, onde podemos citar a gestão de risco e do fornecimento de serviços e produtos personalizados.

Um setor especializado em contabilidade de custos fica responsável por controlar os riscos de mercado, liquidez, operacional e de crédito. A gestão de risco é feita em conjunto com a equipe das instituições que tem foco no tema estratégia, para assim contabilizar todos os riscos existentes.

Por conta da pandemia do Novo Coronavírus as principais instituições financeiras privadas do país tiveram os ganhos financeiros impactados, mas ainda assim lucraram $R \$ 51,8$ bilhões em 2020. No ano passado o lucro líquido recorrente dos 3 maiores bancos privados do Brasil (Itaú, Bradesco e Santander) foi o menor desde o ano de 2016. (FERRARI, 2021)

Com queda de $24,7 \%$ em comparação com 2019 , quando somou $R \$ 68,8$ bilhões. (FERRARI, 2021) 
Para contextualizar essas informações o Banco Itaú é um bom exemplo a ser dado e pode servir como panorama para entender a atual situação financeira do país.

O Banco Itaú apresentou em suas demonstrações contábeis do 4ํㅜ trimestre de 2020 uma redução no custo do crédito em $\mathrm{R} \$ 286$ milhões em relação ao trimestre anterior. Já no primeiro trimestre de 2021 apresentou uma redução em comparativo ao trimestre anterior uma redução de $\mathrm{R} \$ 1.992$ milhões. (FERRARI, 2021) (ITAÚ, 2020)

Com impacto da economia nacional por conta da pandemia, torna-se cada vez mais pertinente o aperfeiçoamento da contabilidade de custos das instituições financeiras, devido à queda no poder aquisitivo da população de uma forma geral.

Nas instituições, por haver uma grande facilidade de aplicações financeiras, os dados dos seus clientes tendem a ser sigilosos, o que faz os clientes se sentirem confiantes de que nenhuma transação será violada, mas também pode haver riscos de formas gerenciais.

As atividades de gerenciamento nas instituições financeiras são realizadas por estruturas próprias e especializadas, conforme objetivos, políticas, estratégias, processos e sistemas representados em cada um desses riscos, onde a contabilidade de custo tende de fornecer dados importantes para a tomada de decisão.

A importância da contabilidade de custos nas instituições financeiras é desenvolver uma forma de trabalho, para que seja possível, apurações contábeis de custo, onde torna-se imprescindível que, exista preliminarmente, uma organização que sistematize os registros e os diversos controles nos serviços prestados as organizações.

De acordo com Oliveira et al. (2008), sabe-se que a Contabilidade de Custos há muito tempo vem deixando de ser uma simples ferramenta contábil. Com avanços nesta área e o aperfeiçoamento das apurações de custos, a Contabilidade de 
Custos vem sendo uma forma essencial nas organizações, e contribui com as informações para contabilidade gerencial num processo decisório.

\section{CONSIDERAÇÕES FINAIS}

Diante deste contexto, é indispensável que todo empreendimento para seu bom funcionamento obtenha uma boa gestão empresarial que consiga planejar, captar e gerenciar os recursos financeiros, operacionais e humanos, entretanto, como em todos os âmbitos nas organizações há riscos e é necessário saber como administrálos.

Fica cada vez mais evidente a necessidade da contabilidade de custos nas instituições financeiras do país, sempre visando levar informações relevantes, tempestiva e confiáveis aos seus usuários. O cenário econômico atual está em um momento atípico, é difícil comparar com anos anteriores, a situação das instituições financeiras ficou bem diferente do planejado.

A função dessas instituições financeiras diante de tal situação adversa em que o mundo está passando é de grande importância por dar continuidade no ciclo econômico e fazendo com que as coisas voltem ao normal gradativamente. Continuar fornecendo serviços que são essenciais à sociedade, seja oferecendo empréstimos, gerenciado patrimônio e investindo, realizando pagamentos, transferindo valores, pois todos precisam deles, sendo assim é essencial que haja uma contabilidade capaz de gerir informações de custos com a melhor qualidade possível aos seus usuários.

Portanto, tamanha a relevância para a economia do Brasil, as instituições financeiras são fatores de ligação entre a população e oportunidade de crédito, o poder aquisitivo em mercado. Saber gerenciar a contabilidade de custos é uma ferramenta e vantagem em um ambiente competitivo. 


\section{REFERÊNCIAS}

ALVES, Carlos A. de M.; CHEROBIN, Ana Paula M. S. Análise do nível de divulgação do risco operacional segundo recomendações do Comitê da Basiléia: Estudo em bancos do país e do exterior. Salvador. $30^{\circ}$ Encontro da Enanpad. 2006.

ASSAF NETO, Alexandre. Mercado Financeiro. 9. ed. São Paulo: Atlas, 2009.

BRASIL. Lei no 4.595, de 31 de dezembro de 1964. Disponível em: < http://www.planalto.gov.br/ccivil_03/leis//4595.htm > Acesso em 01 de Julho de 2021.

FERREIRA, Laura Cristina Gastão. 2012. As Instituições Financeiras na Economia: Uma análise empírica do caso português. Disponível em: < https://www.repository.utl.pt/bitstream/10400.5/10553/1/DM-LCGF-2012.pdf>. Acesso em 07 de jun. 2021.

FEREIRA, Laura Cristina Gastão. As Instituições Financeiras na Economia: Uma análise empírica do caso português. 2012. Disponível em: < https://www.repository.utl.pt/bitstream/10400.5/10553/1/DM-LCGF-2012.pdf>. Acesso em 07 de jun. 2021.

FERRARI, Hamilton. Lucro dos 3 maiores bancos privados em 2020 foi o menor em 4 anos. Poder 360. Fevereiro de 2021. Disponível em: < https://www.poder360.com.br/economia/lucro-dos-3-maiores-bancos-privados-em2020-foi-o-menor-em-4-anos/ > Acesso em 16 de Julho de 2021.

ITAÚ. 4T 20. Demonstrações contábeis completas em IFRS. Relatório do auditor independente sobre as demonstrações contábeis consolidadas. 31 de Dezembro de 2020. Disponível em: < https://www.itau.com.br/relacoes-cominvestidores/Download.aspx?Arquivo=DQiqC7Br+09tg0tm YVqmvg==> Acesso em 02 de agosto de 2021. 
ITAÚ. 1T 21. Análise gerencial da operação e demonstrações contábeis completas 1ํ trimestre de 2021. 2021. Disponível em: < https://www.itau.com.br/relacoes-com-

investidores/Download.aspx?Arquivo=ymfB6HDBirU+W0c8ruzzhA== > Acesso em 02 de agosto de 2021.

OLIVEIRA, A. A., et al. Contabilidade de Custos - Temas Atuais. Curitiba: Juruá. 2008.

SALOMÃO NETO, Eduardo. Direito bancário. São Paulo: Atlas, 2011.

Enviado: Junho, 2021.

Aprovado: Setembro, 2021 